Relations industrielles

Industrial Relations

\title{
Labor Law, vol. I, by Joseph Alton Jenkins, The W. H. Anderson Company, Cincinnati, 1960, 528 pages.
}

\section{Jean Bernier}

Volume 24, numéro 2, 1969

URI : https://id.erudit.org/iderudit/028032ar

DOI : https://doi.org/10.7202/028032ar

Aller au sommaire du numéro

Éditeur(s)

Département des relations industrielles de l'Université Laval

ISSN

0034-379X (imprimé)

1703-8138 (numérique)

Découvrir la revue

Citer ce compte rendu

Bernier, J. (1969). Compte rendu de [Labor Law, vol. I, by Joseph Alton Jenkins, The W. H. Anderson Company, Cincinnati, 1960, 528 pages.] Relations

industrielles / Industrial Relations, 24(2), 453-453.

https://doi.org/10.7202/028032ar

Tous droits réservés @ C Département des relations industrielles de l'Université Laval, 1969
Ce document est protégé par la loi sur le droit d'auteur. L’utilisation des services d'Érudit (y compris la reproduction) est assujettie à sa politique d'utilisation que vous pouvez consulter en ligne.

https://apropos.erudit.org/fr/usagers/politique-dutilisation/ 
transposées comme telles dans de nouvelles conventions, ce dont les auteurs demeurent conscients. Dans leur esprit, il s'agit plutôt de modèles à partir desquels il est possible de construire de nouvelles clauses adaptées aux situations concrètes.

Toutefois comme le domaine de la convention collective en est un qui évolue très vite, les clauses, tant dans leur contenue, que dans leur formulation, connaissent des changements constants. C'est pourquoi les auteurs ont prévu que l'ouvrage (présenté dans un cahier à feuilles mobiles) serait remis à jour périodiquement. C'est d'ailleurs à cette seule condition qu'il pourra continuer de rendre les services pour lesquels il a été voulu.

\section{Jean BERNIER}

Labor Law, vol. I, by Joseph Alton Jenkins, The W. H. Anderson Company, Cincinnati, 1960, 528 pages.

Le droit du travail aux Etats-Unis est si complexe, son évolution est tellement liée à l'histoire économique et politique de ce pays qu'il est parfois difficile de s'y retrouver ou même de le considérer comme une branche isolée des autres parties du droit. Il ne faut pas oublier non plus les problèmes particuliers que soulèvent l'élaboration et l'application d'un droit du travail dans un état fédéral tel que les Etats-Unis.

C'est dans ce contexte que l'auteur entend faire une étude, la plus complète possible, de la législation du travail dans ce pays en la restituant dans son cadre historique et constitutionnel.

Le premier tome aborde trois grands ordres de problèmes seulement. D'abord les aspects constitutionnels du droit du travail aux Etats-Unis de même que les juridictions des divers tribunaux. La deuxième partie est consacrée à une étude du «National Labor Relations Board $\gg$. Enfin, le dernier chapitre traite des causes de « représentation 》 ou accréditation syndicale devant le «N.L. R.B. », notamment la procédure, la détermination de l'unité de négociation appropriée, le vote, etc.

Les explications sont en général brèves et concises. Par ailleurs, il est intéressant de noter que l'ouvrage, en plus de faire état d'une jurisprudence abondante, rapporte le texte intégral d'un grand nombre de documents qui en constituent un utile complément. C'est ainsi qu'on $\mathrm{y}$ trouve les principales lois du travail, des documents et des formules officielles de N.L.P.B.

L'ensemble constitue un instrument de travail précieux pour le praticien comme pour le professeur ou le chercheur.

Avant de porter un jugement global sur l'ouvrage, il sera intéressant de prendre connaissance des trois tomes à venir qui porteront sur les «pratiques déloyales » tant de la part de l'employeur que de la part du syndicat et sur certaines autres questions relatives aux injonctions, aux conflits d'urgence nationale, à la poursuite en dommage et le reste.

Jean BERNIER

Wages in Practice and theory, by Robert Ozanne, the University of Wisconsin Press, Madison, 1968, 181 pages.

Le professeur Ozanne nous propose une étude propre à l'économique du travail et aux relations industrielles. Par une étude de cas, il nous amène à reconsidérer, par la pratique, des hypothèses fondamentales des théories du salaire et des théories du comportement. Nous devons peut-être à Robert Ozanne une des premières grandes études de cas dans le domaine des relations industrielles. L'expérience est d'une valeur extrêmement importante, car elle annonce possibles de multiples études du genre après environ 100 ans de pratique des relations industrielles; elle présente aux relations industrielles une autre méthode de recherche, méthode qu'ont déjà utilisée les sciences plus anciennes.

Grâce à la collaboration de la famille McCormick, le professeur Ozanne a pu se constituer, à partir des feuilles de paie et de la correspondance de la compagnie (McCormick and International Harvester), une histoire des relations industrielles dans cette compagnie. Les résultats étonnent: d'abord, nous avons là reconstitué l'histoire statistique des variations de salaires entre 1860 et 1960 , histoire située dans un contexte économique national. L'auteur a donc pu étudier les rapports entre les grandes crises 